\title{
Early warning thresholds for partially saturated slopes in volcanic ashes
}

\author{
John Eichenberger, Alessio Ferrari, Lyesse Laloui* \\ Ecole Polytechnique Fédérale de Lausanne (EPFL), School of Architecture, Civil and Environmental Engineering (ENAC), Laboratory for Soil Mechanics (LMS), EPFL-ENAC-LMS,
} Station 18, CH-1015 Lausanne, Switzerland

\section{A R T I C L E I N F O}

\section{Article history:}

Received 20 March 2012

Received in revised form 15 October 2012

Accepted 5 November 2012

\section{Keywords:}

Partially saturated soil

Volcanic ash

Slope stability

Early warning threshold

Rain infiltration

Seepage analysis

\begin{abstract}
A B S T R A C T
Rainfall-induced landslides in steep soil slopes of volcanic origin are a major threat to human lives and infrastructure. In the context of constructing early warning systems in regions where extensive data on landslide occurrences and associated rainfall are inexistent, physically-based tools offer the possibility to establish thresholds for measurable field quantities. In this paper, a combined finite element infinite slope model is presented to study the transient hydraulic response of volcanic ash slopes to a series of rainfall events and to estimate seasonal safety factors. Furthermore, analytical considerations of partially saturated infinite slopes are made to define capillary stress thresholds for a landslide early warning system.
\end{abstract}

(c) 2012 Elsevier Ltd. All rights reserved.

\section{Introduction}

Two rainfall-induced landslides in volcanic ashes, which occurred towards the end of the wet season of 2005, caused material damage and production losses in a quarry situated along the hillslopes of Irazu volcano in Costa Rica. As a consequence of these landslide events, the quarry owner decided to install an early warning system to reduce the landslide risk for the future. Since shallow rainfall-induced landslides are hydraulically-driven firsttime failures, it was decided to include as primary element continuous in situ pore water pressure, water content and rainfall measurements in the early warning system and to add alarm thresholds for those field variables. Due to the absence of information on past landslide events and associated rainfall patterns for the establishment of empirical thresholds, an alternative procedure is presented in this paper to establish thresholds in a preliminary phase and to study the pore water pressure response and safety factors of volcanic ash slopes throughout a rainy season.

Rainfall-induced landslides in steep soil slopes of volcanic origin are common around the world and have caused massive destruction and the loss of lives (Italy [1,2]; Hong Kong [3]; Central America [4-6]). In particular, in Central America, the populated areas surrounded by steep volcano slopes are highly vulnerable to rainfall- and earthquake-induced landslides that are triggered in loose volcanic soils. In 2001, the Las Colinas landslide in El Sal-

\footnotetext{
* Corresponding author. Tel.: +41 2169323 14; fax: +4121693 4153 .

E-mail addresses: john.eichenberger@epfl.ch (J. Eichenberger), alessio.ferrari@epfl.ch (A. Ferrari), lyesse.laloui@epfl.ch (L. Laloui).
}

vador claimed $>500$ casualties [5], and in 1998, thousands of landslides were caused by Hurricane Mitch throughout all of Central America with $>9000$ casualties [7]. In particular, due to the loose structure from the depositional process, narrow grain-size distribution, degree of weathering and collapsibility, failed soil masses from volcanic deposits are often reported to turn into rapid flow slides or debris flows with catastrophic consequences in the runout zones [8]. At the origin, the involved materials are mostly in a state of partial saturation.

In this paper, analytical considerations with an infinite slope model are made to establish preliminary pore water pressure thresholds for partially saturated slopes of variable steepness in the first step. In the second step, a physically-based model that consists of two semi-coupled parts is presented. The first part is a finite element soil column model for the transient analyses of vertical rain infiltration in partially saturated volcanic ash. Based on laboratory results, an empirical relationship that links the volcanic ash coefficient of permeability to the degree of saturation and void ratio is proposed. The latter is shown to have a significant effect on the transient pore water pressure response to rain infiltration. The second part is an infinite slope model for calculating the safety factors in variably saturated soils. This part is coupled to the first part of the model in the sense that the vertical profiles of the pore water pressure and degree of saturation resulting from the transient finite element simulations are used as inputs for calculating the safety factor profiles at each time step. On one hand, the proposed model enables studying the hydraulic response of volcanic ash slopes with different average bulk densities to a series of rainfall events. On the other hand, the transient slope safety 
factors for the range of considered slope angles provide a quantitative appreciation of the effect of different rainfall patterns on slope stability.

\section{Physically-based approach for the preliminary establishment of early warning thresholds}

Physically-based models for slope stability analyses at the catchment scale often and primarily consist of a hydraulic model for calculating the pore water pressure diffusion in an idealised slice of a slope as a function of stationary or transient rainfall input. The hydraulic model is coupled to an infinite slope stability model for the subsequent calculation of slope safety factors [9-13]. Although this type of model is constrained by its simplified assumptions regarding the hydraulic and mechanical boundary and initial conditions, as well as a rigid body assumption for the mechanical description, it presents the following advantages.

1. The model is a reasonable starting point for cases in which field measurements are not available or the data is of poor quality. This is not the case for empirical methods that rely on extensive landslide occurrence and associated rainfall data for establishing rainfall intensity-duration thresholds.

2. For cases in which planar slope failure surfaces are prevailing, critical pore water pressure or soil water content levels can be calculated at different soil depths and for variable slope angles and soil strength properties. This is of particular interest for the preliminary establishment of pore water pressure thresholds for single slope scale landslide early warning systems for which field measurements are not available.

3. Thresholds that are established with physically-based models are more objective than those established by means of empirical methods. Such thresholds result from general equilibrium considerations, while empirical methods rely mostly on a subjective definition of thresholds, separating rainfall events that lead to landslides from those that do not.

4. For cases in which the hydraulic model accurately reproduces the governing time-dependent subsurface flow processes and planar slope failure surfaces are prevailing, critical rainfall thresholds and actual slope safety factors can systematically be established as a function of local rainfall history and for variable slope angles and soil strength properties.

5. In conjunction with a grid-based Geographic Information System (GIS), a relative susceptibility index can be calculated for each cell unit and assembled in a relative landslide susceptibility map $[6,8,14-16]$.

The first three above-mentioned points particularly apply in the present case concerning potentially unstable slopes in the mining area of the Irazu volcano and suggest the use of such a physicallybased model type. The hydromechanical behaviour of the involved volcanic ash has been characterised by means of a comprehensive experimental laboratory testing program $[17,18]$, thus enabling the use of a physically-based model for seepage and slope stability analyses. Compared to more detailed geomechanical models at the local slope scale [19-21], the model described hereafter allows a pragmatic, general exploration of the effects of a series of wet season rainfall events on slope stability as a function of soil hydraulic and strength properties, as well as slope inclination.

\subsection{General description of the finite element model for seepage analyses}

Steep slopes between $35^{\circ}$ and $50^{\circ}$ in the surrounding area of the quarry are composed of loosely cemented, normally consolidated volcanic air-fall ash deposits or colluvia [22]. The volcanic ash deposits are fairly homogeneous with the presence of very few blocks. Depending on the slope angle, the thickness of the ash cover varies between $5 \mathrm{~m}$ and $30 \mathrm{~m}$ [22]. For the transient calculation of rain infiltration and pore water pressure diffusion in the volcanic ash deposits, a finite element soil column model is setup as shown in Fig. 1. The model is constructed using the finite element code LAGAMINE $[23,24]$. The model represents a homogeneous, isotropic soil column that is $6 \mathrm{~m}$ high, $1 \mathrm{~m}$ wide and composed of $10 \times 70$ quadrilateral Q8P8 finite elements ( 8 nodes with quadratic shape functions for solid displacement and pore water pressure). Because the soil cover is shallow, a passive pore air pressure $\left(p_{a}\right)$ that is equal to the atmospheric pressure $\left(p_{a t m}\right)$ is assumed.

The mass conservation for the pore fluid is given by the following equation:

$\frac{\partial\left(n S_{r} \rho_{w}\right)}{\partial t}+\nabla \cdot\left(\rho_{w} n S_{r} \boldsymbol{v}_{w}\right)-Q^{s}=0$,

where $n(-)$ is the soil porosity, $S_{r}(-)$ represents the degree of saturation, $\rho_{w}\left(\mathrm{~kg} / \mathrm{m}^{3}\right)$ is the intrinsic water mass density, $\boldsymbol{v}_{\boldsymbol{w}}(\mathrm{m} / \mathrm{s})$ represents the velocity of water and $Q^{s}\left(\mathrm{~kg} / \mathrm{m}^{3} \mathrm{~s}\right)$ is the specific rate source/sink. Nodal displacements are impeded for a purely hydraulic analysis. Here, $n S_{r} \boldsymbol{v}_{\boldsymbol{w}}=\boldsymbol{q}_{\boldsymbol{w}}$ is the mean velocity of water given by Darcy's law for variably saturated soils,

$\mathbf{q}_{\boldsymbol{w}}=\frac{\gamma_{w} \boldsymbol{K}^{\mathrm{int}} \cdot k_{r, w}}{\mu_{w}} \cdot \nabla\left[\left(\frac{p_{w}}{\gamma_{w}}\right)+z\right]$

where $\boldsymbol{K}^{\text {int }}\left(\mathrm{m}^{2}\right)$ is the intrinsic permeability of the medium, $k_{r, w}(-)$ is the water relative permeability, $\mu_{w}(\mathrm{~kg} / \mathrm{ms})$ is the fluid dynamic viscosity and $\gamma_{w}\left(\mathrm{~N} / \mathrm{m}^{3}\right)$ is the unit weight of water. The governing Eq. (1) is closed by introducing the equation of state for pore water and a constitutive law that relates the degree of saturation $\left(S_{r}\right)$ to the matric suction $\left(s=p_{a t m}-p_{w}\right)$. Details regarding the water retention curve and water relative permeability function are given in the next section. The equation of state for pore water is written as

$\frac{\partial \rho_{w}}{\partial t}=\frac{\rho_{w}}{\chi_{w}} \frac{\partial p_{w}}{\partial t}$,

where $1 / \chi_{w}\left(\mathrm{~Pa}^{-1}\right)$ is the compressibility of water. Eq. (1) can now be rewritten in a pressure form as

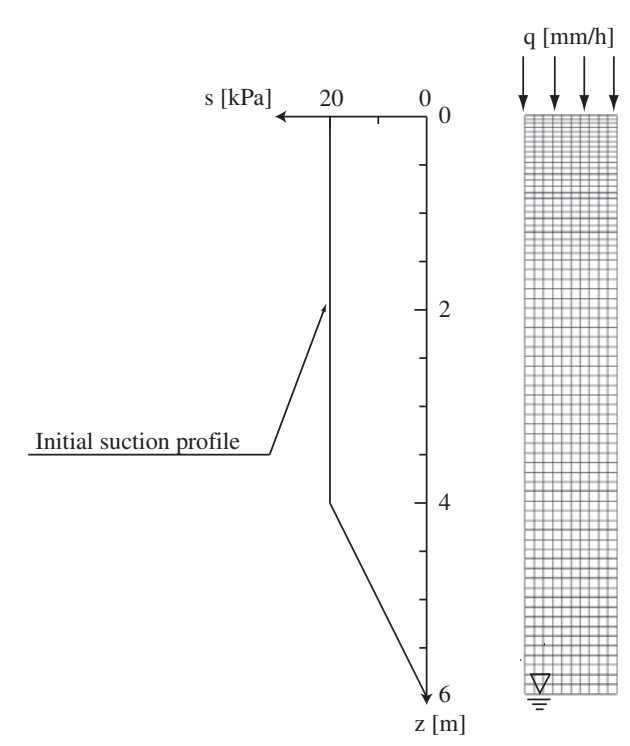

Fig. 1. The finite element mesh of an ash column with hydraulic boundary and initial conditions 
$\frac{\rho_{w} n S_{r}}{\chi_{w}} \frac{\partial p_{w}}{\partial t}+\rho_{w} n \frac{\partial S_{r}}{\partial p_{w}} \frac{\partial p_{w}}{\partial t}+\nabla \cdot\left(\rho_{w} \boldsymbol{q}_{w}\right)-Q^{s}=0$

The ash deposits above the quarry are primarily in a partially saturated state. Temporary seeping water was detected at the front escarpment of the quarry. No groundwater table was detected in borings further downslope in the quarry [25]. In the absence of pore water pressure measurements, a bilinear hydrostatic-constant negative pore water pressure distribution up to $20 \mathrm{kPa}$ is set as the hydraulic initial condition (Fig. 1). The pore water pressure at the bottom boundary is fixed at zero to allow the infiltrated water to flow out of the model once it reaches the lower boundary. This enables a transient analysis over the complete wet season but limits the model application to the top-down matric suction loss mechanism because a groundwater table build-up is not simulated.

Rainfall is simulated through the application of a time-dependent water flux at the top boundary. If the soil reaches saturation at the top boundary, the boundary condition switches from a flux to a pressure boundary condition to avoid water ponding at the slope surface. The effects of evapotranspiration are neglected in the present simulations, as they only seem to play a marginal role during a wet season [26], and the lack of in situ measurements do not justify a more detailed description of the hydraulic processes at this point.

To estimate the temporal rainfall distribution, a characteristic rainfall histogram of a location at comparable altitude and orientation was taken as reference for this analysis (Fig. 2) [27]. Characteristic rainfall events have an approximate duration of $6 \mathrm{~h}$. Over $70 \%$ of the total precipitation occurs within the first $2 \mathrm{~h}$, underlining the high intensity and short duration of rainfall in Costa Rica. The hydrological basin of the mining area is very small, which allows considering a uniform rainfall distribution for the area despite the generally high spatial variability of precipitation. The particular character of rainfall is accounted for in the model by distributing the daily rainfall over $6 \mathrm{~h}$ in 10-min intervals according to an idealised rainfall pattern, as illustrated in Fig. 2. This idealised pattern represents a polynomial fit of the characteristic rainfall pattern.

\subsection{Hydraulic characteristics}

A principal concern for analysing the pore water pressure diffusion in partially saturated soils by means of transient numerical simulations is the assessment of the soil water retention behaviour and permeability. In the context of a comprehensive experimental study regarding the hydromechanical behaviour of volcanic ash

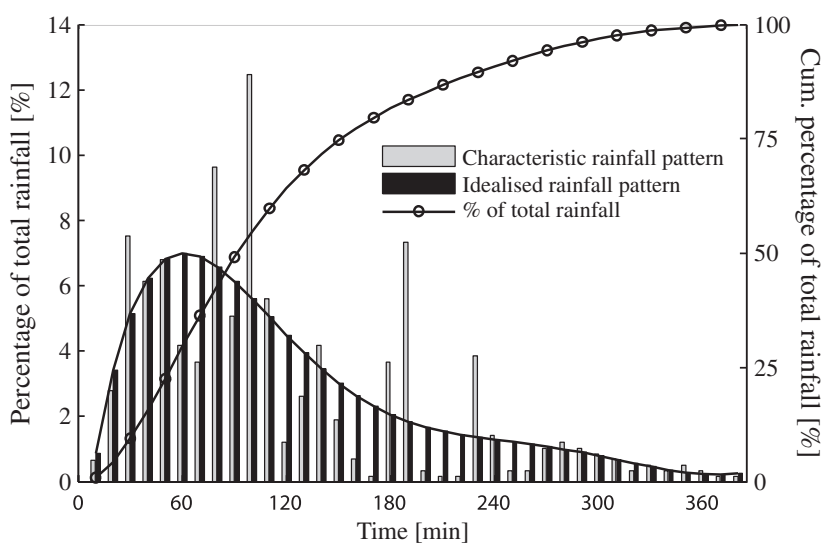

Fig. 2. Rainfall distribution for a single event. The idealised rainfall pattern for numerical simulations is obtained with polynomial fitting. The corresponding cumulative percentage of total rainfall is in agreement with the reported $70 \%$ total rainfall occurring in the first $2 \mathrm{~h}$. The idealised pattern is applied to the daily rainfall data estimated for the mining area.
$[17,18]$, a suction-controlled pressure plate apparatus was used to establish the soil water retention curve. The test results in terms of degree of saturation are plotted against matric suction for a target void ratio $e=1.5$ in Fig. 3. The data points indicate a low air entry value $\left(s_{E}\right)$ of approximately $2 \mathrm{kPa}$, a residual degree of saturation $\left(S_{\text {res }}\right)$ of approximately $3 \%$ and a steep, sloped curve characteristic for a narrow grain size distribution. In the most general case, the soil water retention curve features a capillary hysteresis combined with a void ratio dependency [28]. In the present case, however, test results for target void ratios in the range 1.35-1.65 showed no significant variations from each other, and volumetric deformations during complete drying paths were limited $[17,18]$. The latter $S_{r}-s$ behaviour was also observed under low vertical stresses on ash deposits from southern Italy by Sorbino and Foresta [29]. Additionally, test results along main drying and wetting paths indicated no significant hysteretic effects $[17,18]$. As a consequence of these observations, the use of a single soil water retention curve of the Van Genuchten type [30] is justified,

$S_{r}=S_{\text {res }}+\frac{1-S_{\text {res }}}{\left[1+(\alpha S)^{n}\right]^{m}}$

The results of the curve fitting are shown in Fig. 3, and the numerical values of the model parameters are given in Table 1. For determining the saturated ash coefficient of permeability in the field, two samples were taken at depths of $0.5 \mathrm{~m}$ and $5 \mathrm{~m}$ [22]. The saturated coefficients of permeability $\left(k_{w}^{\text {sat }}\right)$ are reported to be approximately $2 \times 10^{-5} \mathrm{~m} / \mathrm{s}$ and $2.6 \times 10^{-6} \mathrm{~m} / \mathrm{s}$ for the samples at $0.5 \mathrm{~m}$ and $5 \mathrm{~m}$, respectively [22]. Constant head permeability tests conducted in the laboratory on reconstituted samples compacted at different void ratios in a triaxial cell yielded compa-

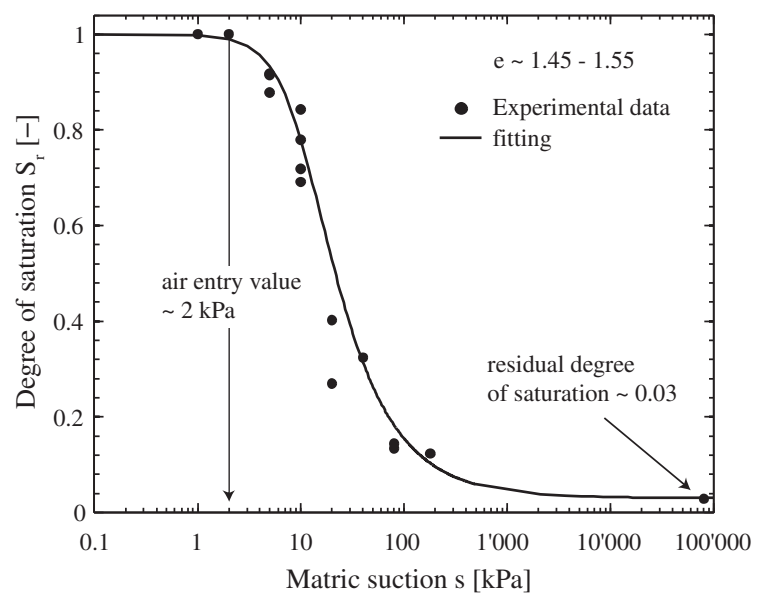

Fig. 3. The experimental data and best fit for the soil water retention curve of volcanic ash.

Table 1

List of parameters for the soil water retention curve and coefficient of permeability.

\begin{tabular}{|c|c|c|c|}
\hline \multicolumn{4}{|l|}{ Retention model } \\
\hline & $\alpha$ & 1st VG parameter & $0.91(1 / \mathrm{m})$ \\
\hline & $n$ & 2nd VG parameter & 2.19 \\
\hline & $m$ & 3rd VG parameter & 0.42 \\
\hline & $S_{\text {res }}$ & Residual degree of saturation & 0.03 \\
\hline \multicolumn{4}{|l|}{ Flow model } \\
\hline \multirow[t]{2}{*}{ Saturated soil } & $K^{i n t, 0}$ & $\begin{array}{l}\text { Intrinsic isotropic permeability } \\
\text { at reference void ratio } e_{r e f}=1\end{array}$ & $4.8 \times 10^{-13} \mathrm{~m}^{2}$ \\
\hline & $c_{k}$ & 1st fitting parameter & 6 \\
\hline \multirow{2}{*}{$\begin{array}{l}\text { Partially } \\
\quad \text { saturated soil }\end{array}$} & $c_{m}$ & 2nd fitting parameter & 53 \\
\hline & $c_{l}$ & 3rd fitting parameter & -25.4 \\
\hline
\end{tabular}


rable results with saturated coefficients of permeability that varied from $10^{-4} \mathrm{~m} / \mathrm{s}$ for a void ratio of $e=1.7$ to $8.5 \times 10^{-6} \mathrm{~m} / \mathrm{s}$ for $e=1.1$ [17].

The soil's isotropic coefficient of permeability $\left(k_{w}\right)$ for variably saturated conditions is expressed as

$k_{w}\left(S_{r}, e\right)=\frac{\gamma_{w} K^{\text {int }}}{\mu_{w}} \cdot k_{r, w}$

Based on the experimental results, the isotropic, intrinsic permeability of the volcanic ash is expressed as a function of the void ratio $(e)$ by the following empirical relationship:

$K^{\text {int }}=K^{\text {int }, 0} e^{c_{k}}$,

where $K^{i n t, 0}$ is the intrinsic, isotropic permeability for a reference void ratio of $e_{r e f}=1$ and the exponent $c_{k}$ is a fitting parameter. The Brooks and Corey relationship [33] is suitable for expressing the water relative permeability $\left(k_{r, w}\right)$ in the unsaturated range:

$k_{r, w}=S_{r}^{\lambda}$.

In addition, the dependency on the void ratio is accounted for with the exponent $\gamma$, and

$\lambda=c_{l} \cdot e+c_{m}$,

where $c_{l}$ and $c_{m}$ are fitting parameters. The results of the calibrated flow model are superposed to the experimental data in Fig. 4. The fitting parameters and their values are summarised in Table 1. The coefficient of permeability of the soil in the unsaturated range was back-calculated using the transient soil response in terms of the water volume exchange for the time recorded during suctioncontrolled pressure plate tests [17]. The water volume inflow recorded for each matric suction increment was interpreted by applying the method proposed by Kunze and Kirkham [31], which is a revised formulation of Gardner's analytical solution [32] of Richard's equation for water flow in unsaturated soils, additionally considering the impedance of the ceramic disc. As a result of the suction-controlled oedometer tests, the water relative permeability as a function of the degree of saturation could be determined for different void ratios (Fig. 4). The experimental data for the water relative permeability varies between $5 \times 10^{-6}$ and $10^{-4} \mathrm{~m} / \mathrm{s}$. The water relative permeability function in Eq. (8) was fitted over this data range and is assumed valid for higher values of water relative

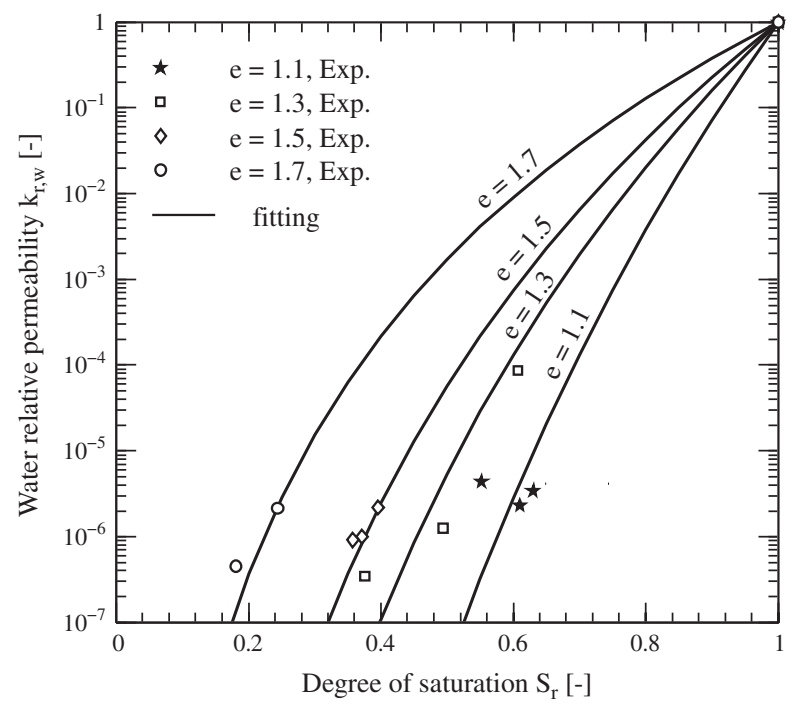

Fig. 4. Evolution of soil water relative permeability with the degree of saturation and void ratio. permeability. Notably, for a given degree of saturation variation between 0.3 and 1 for a matric suction in the field between 40 and $0 \mathrm{kPa}$, the soil's water relative permeability varies accordingly between seven orders of magnitude. The strong variations of permeability in the unsaturated range in conjunction with the steep slope observed in the retention curve favours a saturation of the soil from the top-down during intense rainfall events. However, as shown in Section 4 by means of numerical simulations, the strong dependency of water relative permeability on void ratio yields in significantly different transient hydraulic slope responses.

\subsection{Slope stability analyses}

The results obtained from finite element simulations in terms of vertical profiles of matric suction and degree of saturation are used in the second step to calculate safety factor profiles and their minimum values for different slope angles and given soil strength properties. The volcanic ash is characterised as a cohesionless silty sand (48\% sand-size and 50\% silt-size fractions) with a friction angle of $\varphi^{\prime}=35.5^{\circ}[17,18]$. Infinite slope stability analyses [34] are often used in the context of shallow landslides because its key assumptions are adequate enough for in situ conditions (i.e., failure surface running parallel to the ground surface and a very long slope relative to the thickness of an unstable mass) in many cases. The limited depth of the volcanic ash cover on steep slopes favours translational slides. Considering saturated conditions without the flow of groundwater, the factor of safety $(F o S)$ can be written in terms of Terzaghi's effective stress as

$F o S=\frac{\tau_{f}}{\tau_{m}}=\frac{c^{\prime}+\sigma_{n}^{\prime} \tan \varphi^{\prime}}{\tau_{m}}=\frac{c^{\prime}+\left[\left(\gamma z \cos ^{2} \beta\right)-p_{w}\right] \cdot \tan \varphi^{\prime}}{\gamma z \cos \beta \sin \beta}$

Here, $\tau_{f}$ is the available shear strength of the soil, $\tau_{m}$ represents the mobilised shear strength, $c^{\prime}$ is the cohesion intercept, $\sigma_{n}^{\prime}$ represents the effective stress normal to the failure plane, $\gamma$ is the soil's total saturated unit weight, $\beta$ is the slope angle and $z$ represents the considered depth of the Mohr-Coulomb failure plane. For unsaturated soils, Bishop [35] proposed the following single effective stress:

$\boldsymbol{\sigma}^{\prime}=\boldsymbol{\sigma}-p_{a} \mathbf{1}+\chi\left(p_{a}-p_{w}\right) \mathbf{1}$,

where $\boldsymbol{\sigma}$ is the total stress tensor, $\mathbf{1}$ is the identity tensor and $\chi$ (Bishop's parameter) is a factor that accounts for the fluid compressibilities and volume fractions [36]. Based on this effective stress, Bishop and Blight [37] interpreted shear strength data with

$$
\begin{aligned}
\tau & =c^{\prime}+\sigma_{n}^{\prime} \tan \varphi^{\prime}=c^{\prime}+\left[\left(\sigma_{n}-p_{a}\right)+\chi\left(p_{a}-p_{w}\right)\right] \tan \varphi^{\prime} \\
& =c^{\prime}+\left(\sigma_{n e t, n}+\chi s\right) \tan \varphi^{\prime},
\end{aligned}
$$

where $\sigma_{\text {net, } n}=\sigma_{n}-p_{a}$ is the net stress normal to the Mohr-Coulomb failure plane. Amongst others, Schrefler [38] proposed to replace $\chi$ by $S_{r}$ in Bishop's effective stress (Eq. (11)), which was subsequently designated as the generalised effective stress within the elasto-plastic modelling context of partially saturated soils [36,39]. Considering this generalised effective stress and the fact that friction angle does not change with matric suction [36], the critical state line is unique for all saturation states. Thus, Eq. (10) can be rewritten for unsaturated soils as

$$
\begin{aligned}
\text { FoS } & =\frac{c^{\prime}+\left[\left(\bar{\gamma} z \cos ^{2} \beta-p_{a}\right)+S_{r}\left(p_{a}-p_{w}\right)\right] \cdot \tan \varphi^{\prime}}{\bar{\gamma} z \cos \beta \sin \beta} \\
& =\frac{c^{\prime}+\left[\left(\bar{\gamma} z \cos ^{2} \beta\right)+S_{r} s\right] \cdot \tan \varphi^{\prime}}{\bar{\gamma} z \cos \beta \sin \beta},
\end{aligned}
$$

where $\bar{\gamma}$ is the average soil unit weight down to depth $z$ of the failure plane. The effective stress acting normal to the failure plane has a total stress component that is dependent on the slope angle $(\beta)$, average soil unit weight and capillary stress component $\left(S_{r} s\right)$. The 
use of the generalised effective stress with $\chi=S_{r}$ for shear strength prediction is adequate for granular soils and fine granular soils dominated by the capillary effects [40]. This is the case for the present volcanic ash with a residual degree of saturation of only $3 \%$. The chosen generalised effective stress formulation implicitly requires an accurate description of the soil water retention behaviour $[36,39]$. With regards to the total stress component, a saturated soil unit weight is often considered to be a conservative, safe option in geotechnical design [41]. However, for a more accurate study of wetting- and drying-induced slope safety factor variations in volcanic ash deposits that present a very low dry unit weight at natural water content $\left(\gamma_{d}=9.9 \mathrm{kN} / \mathrm{m}^{3}\right)$ [17], and aside from the changes in effective stresses due to changes in the degree of saturation and matric suction, all of the changes in total stresses that occur due to the added weight of infiltrated water are included. The total unit weight of a variably saturated soil is subsequently calculated in the infinite slope stability model by expressing the average soil unit weight down to depth $z$ as a function of the vertical distribution of degree of saturation and porosity $n$ as

$\bar{\gamma}=\frac{1}{z} \int_{0}^{z}\left\{[1-n(y)] \gamma_{s}+S_{r}(y) n(y) \gamma_{w}\right\} d y$,

where $\gamma_{s}$ is the solid grain unit weight. For calculating the transient safety factors, the average unit soil weight is computed at each time step $(t)$ from the finite element calculation with

$\bar{\gamma}_{t}=\frac{1}{\operatorname{nod}} \sum_{i=2}^{i=n o d}\left\{\left[\frac{\left(2-n_{t, i}-n_{t, i-1}\right)}{2} \gamma_{s}+\frac{\left(S_{r_{t, i}} n_{t, i}+S_{r_{t, i-1}} n_{t, i-1}\right)}{2} \gamma_{w}\right]\left(\left|y_{t, i}-y_{t, i-1}\right|\right)\right\}$.

Here, $\bar{\gamma}_{t}$ is the average soil unit weight at time step $t$, nod is the number of nodes in the finite element mesh combined with the vertical axis from the slope surface down to depth $z, n_{t, i}$, resp. $S_{r_{t i}}$ is the interpolated nodal values of porosity, resp. degree of saturation at node $i$ and time step $t$ and $\left|y_{t, i}-y_{t, i-1}\right|$ is the vertical distance between nodes $i$ and $i+1$. Notably, the values of Gauss point variables are linearly interpolated to nodal values to be consistent with pore water pressures that are computed at the nodes.

\section{Matric suction thresholds for shear failure mechanisms in steep, partially saturated slopes}

Preliminary pore water pressure thresholds for different slope angles can be established with Eq. (13). On one hand, these thresholds can be directly used in an early warning system. On the other hand, comparing real-time field measurements with their respective thresholds allows conclusions regarding the predisposition of a slope to fail. These soil field variable thresholds are also a necessary, although not sufficient, component in determining the precursor rainfall events that will most likely trigger a landslide. Introducing the soil water retention curve in Eq. (13) and setting a minimum acceptable safety factor $\left(F_{0} S_{d}\right)$, the equilibrium equation can be solved for matric suction. Assuming that $F_{0} S_{d}=1$ and a constant dry, saturated, resp. wet soil unit weight, vertical profiles of critical matric suction levels at different depths can be plotted for different slope angles (Fig. 5). Due to the noticeable difference in net normal stresses between dry and saturated loose volcanic ash, the critical matric suction levels vary considerably. Obviously, the most conservative option, although potentially inconclusive for steep slope angles, is to consider the curves with a saturated soil unit weight and to define all matric suction levels below as potentially unstable conditions.

Although the product of matric suction and degree of saturation is a strictly monotonically increasing function with matric suction in the present case, two solutions for Eq. (13) exist. Consider the pore pressure parameter $\left(r_{u}\right)$ of

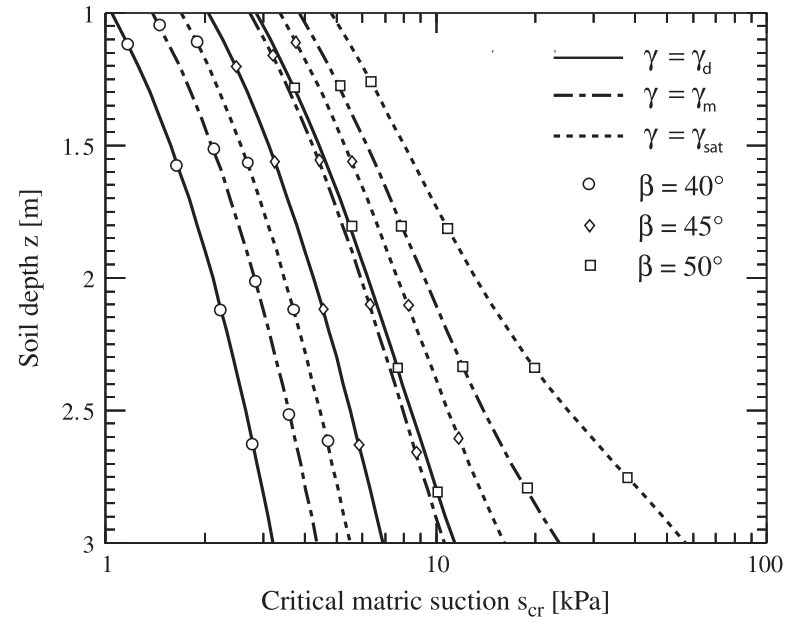

Fig. 5. Vertical profiles of critical matric suction levels for different slope angles $(\beta)$ between $1 \mathrm{~m}$ and $3 \mathrm{~m}$. The profiles are established for a dry soil unit weight $\left(\gamma_{d}\right)$ (lower criterion), a saturated soil unit weight $\left(\gamma_{\text {sat }}\right)$ (upper criterion) and a moist soil unit weight $\left(\gamma_{m}\right)$ (intermediate criterion) corresponding to an average $53 \%$ degree of saturation $(s=20 \mathrm{kPa})$ above the failure plane.

$r_{u}=\frac{p_{w}}{\sigma_{v}}$

where $\sigma_{v}$ is the vertical total stress. Rewriting the expression for capillary stress $\left(S_{r} s\right)$ in unsaturated conditions and for a simplified stress distribution in a soil column yields

$r_{u}=\frac{S_{r} s}{\gamma z}$

Now, Eq. (13) can be rewritten as

$\begin{aligned} \text { FoS } & =\frac{c^{\prime}+\bar{\gamma} z\left(\cos ^{2} \beta+r_{u}\right) \cdot \tan \varphi^{\prime}}{\bar{\gamma} z \cos \beta \sin \beta} \\ & =\frac{c^{\prime}}{\bar{\gamma} z \cos \beta \sin \beta}+\frac{r_{u} \cdot \tan \varphi^{\prime}}{\cos \beta \sin \beta}+\frac{\tan \varphi^{\prime}}{\tan \beta} .\end{aligned}$

For the cohesionless volcanic ash $c^{\prime}=0$ and the critical pore pressure parameter $\left(r_{u, c r}\right)$ at limit equilibrium is given by

$r_{u, c r}=\cos \beta \sin \beta\left(\frac{F o S}{\tan \varphi^{\prime}}-\frac{1}{\tan \beta}\right)=\cos \beta \sin \beta\left(\frac{1}{\tan \varphi^{\prime}}-\frac{1}{\tan \beta}\right)$.

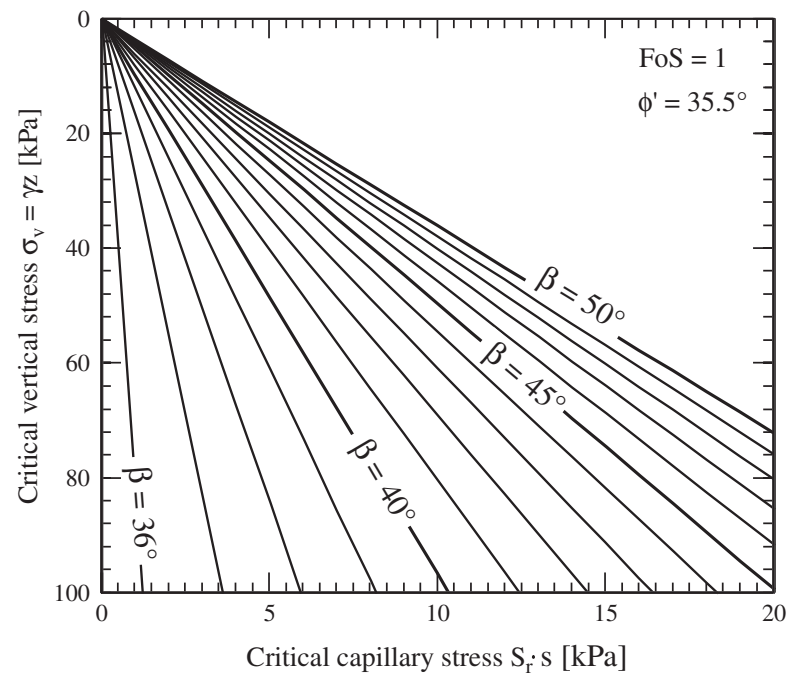

Fig. 6. Slope stability chart. The critical levels of capillary stress are provided as a function of vertical stress $\left(\sigma_{v}\right)$ for different slope angles between $36^{\circ}$ and $50^{\circ}$ $\left(\varphi^{\prime}=35.5^{\circ}, \mathrm{FOS}=1\right)$. 
For a given critical pore pressure parameter, two values for slope angle $\beta$ within the domain $\beta \in\left[0^{\circ}, 90^{\circ}\right]$, satisfying Eq. (19), exist. Given a friction angle of $\varphi^{\prime}=35.5^{\circ}$, the solution of Eq. (19) is unique as long as the slope angle remains smaller than a $\beta_{\max }$ of $62^{\circ}$, which is the case in the present study. The counterintuitive observation of decreasing critical pore pressure parameter with increasing slope angle was already reported by Griffiths et al. [42] for a cohesive frictional soil in saturated conditions with a slope parallel groundwater flow and interpreted through a series of finite element simulations on flat and steep slopes. Considering Eqs. (17) and (19), constructing a stability chart that enables determining the critical level of capillary stress $\left(S_{r} \cdot s\right)$ corresponding to a certain vertical stress $\left(\sigma_{v}\right)$ and slope angle $(\beta)$ between $36^{\circ}$ and $50^{\circ}$ is possible (Fig. 6 ). In this sense and combined with the soil water retention curve, the stability chart serves as a solution to provide an early warning system with matric suction thresholds.

\section{Transient pore water pressure response and seasonal safety factors}

Seasonal precipitation variations in Costa Rica are characterised by a dry season between December and April and a wet season from May to December. Aside from a common precipitation maximum between June and September, a second maximum often occurs between November and December [43]. During the wet season, rainfall is characterised by small duration and high intensity. The particular quarry under consideration is situated in the forested, low mountain humid zone with evergreen vegetation and is characterised by a relatively low mean annual precipitation between 1800 and $2000 \mathrm{~mm}$. The hydrological settings in the mining area were inferred based on available data from the surrounding areas. Fig. 7 shows the average monthly precipitations between 1951 and 2004 and the monthly cumulative rainfall in 2005 for the mining area [22]. The monthly cumulative rainfall of the Santamaria International Airport near the capital San José and $40 \mathrm{~km}$ from the mining site is also plotted. For that station, the daily precipitation data was also available $[44,45]$. Compared with the data from the San José region, the cumulative monthly rainfall is significantly higher in the mining area during the wet season of 2005, surpassing the recorded long-term average monthly precipitation. Because the transient finite element simulation of rain infiltration relies on daily rainfall input, the data from the Santamaria International Airport is used; however, the daily values for each month are multiplied by a factor to adjust the cumulative monthly rainfalls to those of the mining area.

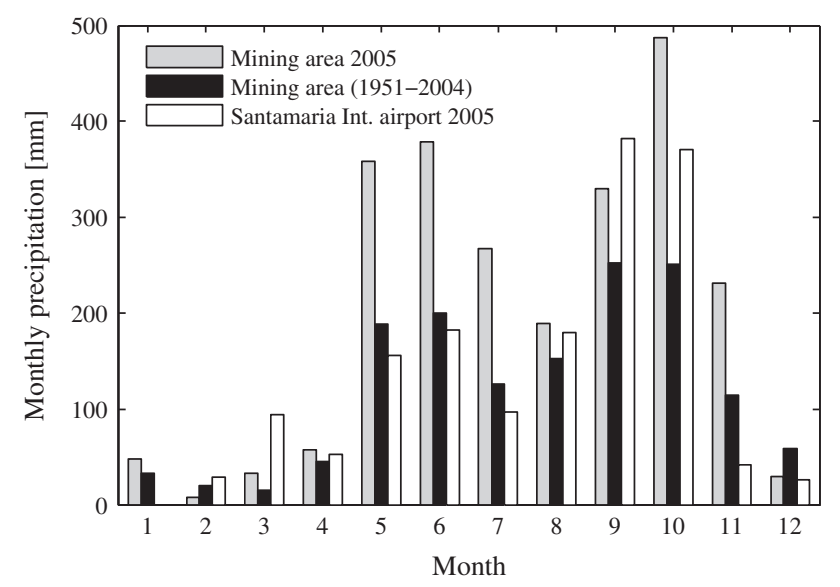

Fig. 7. A comparison between the total monthly precipitation values in the mining area [22] and the Juan Santamaria International Airport [44] for 2005. The rainfall for the months of September, October and November are above average.

\subsection{Effect of void ratio on transient pore water pressure response}

Laboratory results have shown that void ratio changes have a negligible effect on the soil water retention behaviour in the investigated void ratio range between $e=1.1$ and $e=1.7$ [17]. However, for this void ratio range, a significant dependency of the saturated and unsaturated coefficient of permeability on void ratio was found [17]. The soil water permeability was repeatedly identified as a primary governing factor for rainfall-induced landslides [46]. Because the transient hydraulic response of soil to wetting and drying cycles strongly depends on the soil water permeability, the present simulations are run for reference case $A$ with a void ratio of $e=1.6$ corresponding to the void ratio of the recovered samples for laboratory testing, as well as for an additional case B of denser soil $(e=1.2)$, which is arbitrarily chosen within the investigated void ratio range and which is representative for higher confining stresses of approximately $100 \mathrm{kPa}$. The water relative permeability functions for both investigated cases are shown in Fig. 8. For comparison, the curve obtained from the Van Genuchten-Mualem model $[30,47]$ with the soil water retention parameters from Table 1 is also displayed. While the Van GenuchtenMualem model produces a reduction in water relative permeability by an order of magnitude over the relevant range of degree of saturation, the model implemented here, which fits best the experimental results, produces strong permeability variations of $\leqslant 7$ orders of magnitude. For case A and case B, the transient response of the soil to rain infiltration is significantly different depending on its water relative permeability.

A soil cover of $3 \mathrm{~m}$ thickness is considered for the safety factor calculations. The infinite slope stability analysis suggests actually that 3-m thick soil covers on steep slopes with a $50^{\circ}$ angle are always unstable for matric suction values typical for the wet season. Thus, it is reasonable to limit the safety factor analyses to the first $3 \mathrm{~m}$. The influence of the imposed pore water pressure boundary condition at the bottom of the soil column on the pore water pressure distribution within the first $3 \mathrm{~m}$ of soil depth is negligible. Fig. 9, resp. Fig. 10 shows the evolution of matric suction and minimum factor of safety $\left(F o S_{\min }\right)$ for different slope angles $(\beta)$ throughout the wet season from August 1 to December 31 for

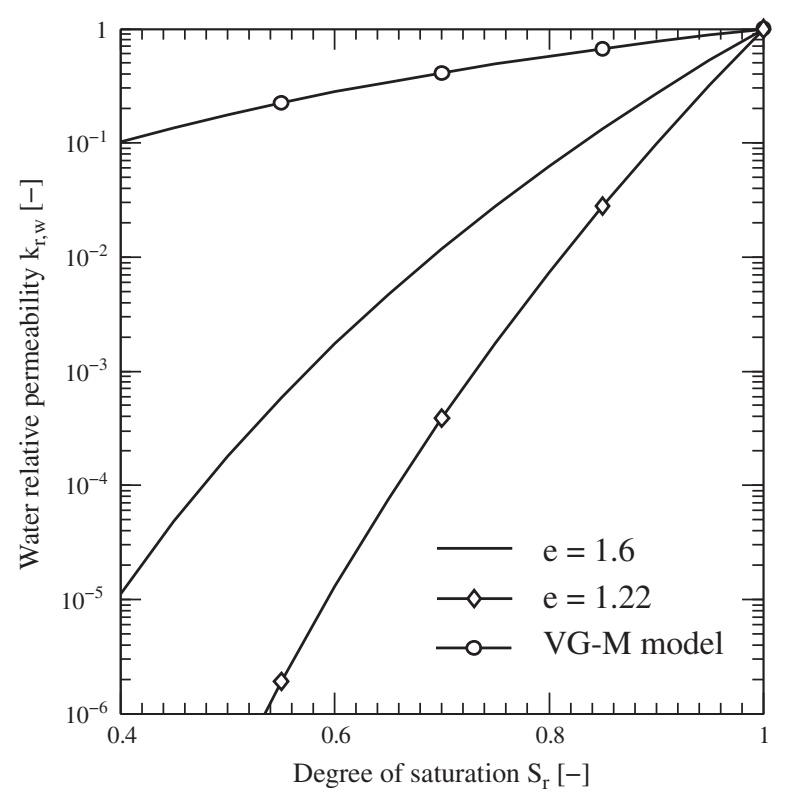

Fig. 8. Water relative permeability functions for the reference case A with an $e=1.6$, case B with an $e=1.2$ and the result obtained from the Van GenuchtenMualem model. 

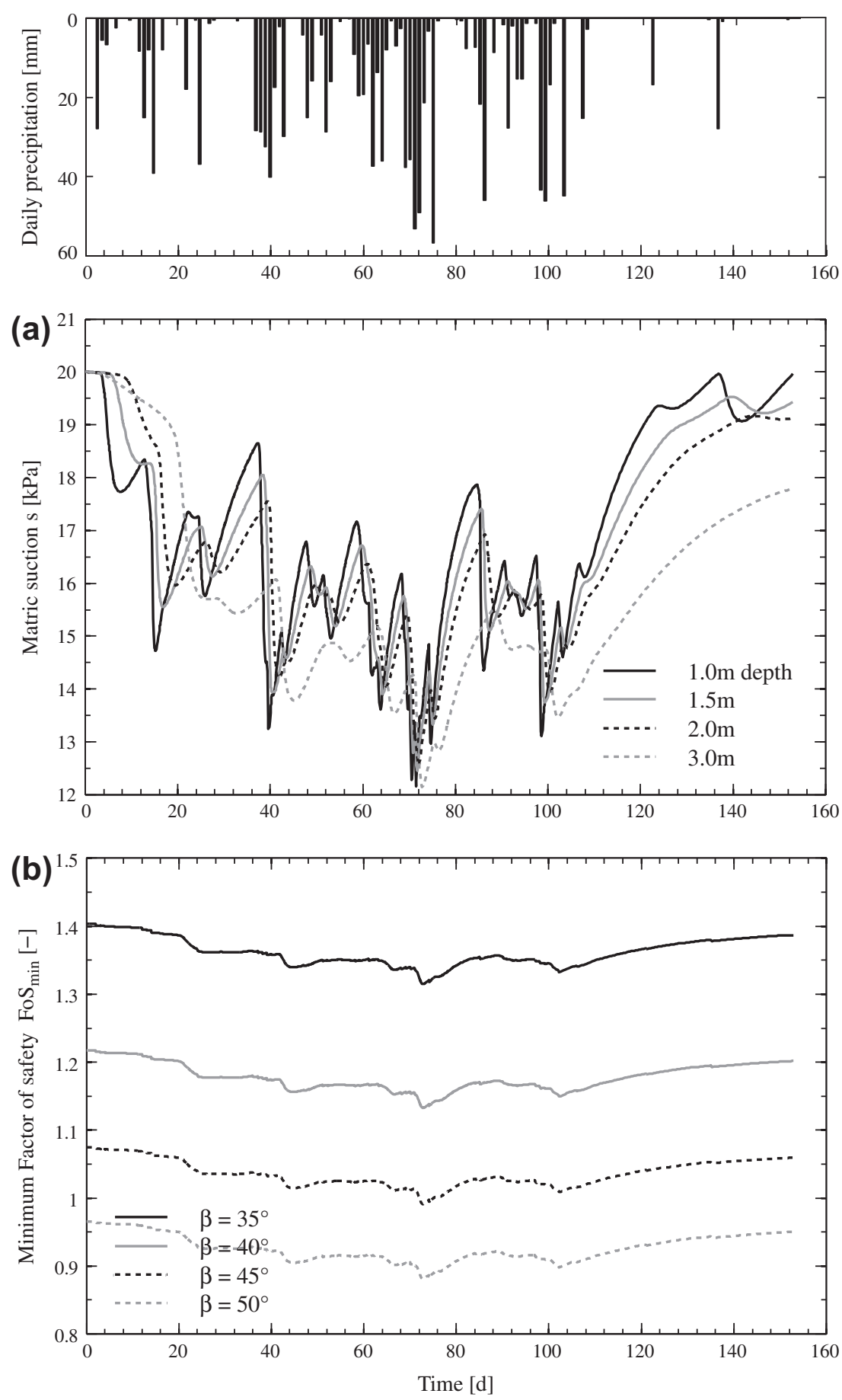

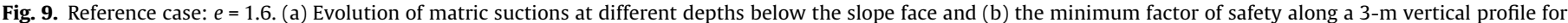
different slope angles $(\beta)$.

reference case $A$, resp. case $B$ at depths varying between 1 and $3 \mathrm{~m}$. The minimum factor of safety at a given time corresponds to the lowest value computed along the vertical soil column profile down to a depth of $3 \mathrm{~m}$. Noticeably, the transient pore water pressure responses differ in terms of magnitude of matric suction loss and delay intervals between rainfall inputs and pore water pressure reactions. While matric suction levels vary between 20 and $12 \mathrm{kPa}$ for case A, more substantial matric suction losses as low as $6 \mathrm{kPa}$ are observed for case B, indicating that the less permeable, partially saturated soil of the latter case requires more time to drain the infiltrated water and subsequently tends to saturate the soil from the top-down.

In case $\mathrm{A}$, the pore water pressure reactions show a delay increasing by 2 days per metre of soil depth with respect to the precursor rainfall event (Fig. 9a). Matric suctions have a tendency to decrease throughout the wet season. Accordingly, the slope safety factors decrease (Fig. 9b). Matric suctions tend to re-increase to as low as $3 \mathrm{~m}$ in soil depth after 10 days with low rainfall amounts (e.g., day 25-35). However, as the soil's water relative permeability decreases again during the drying phase with 

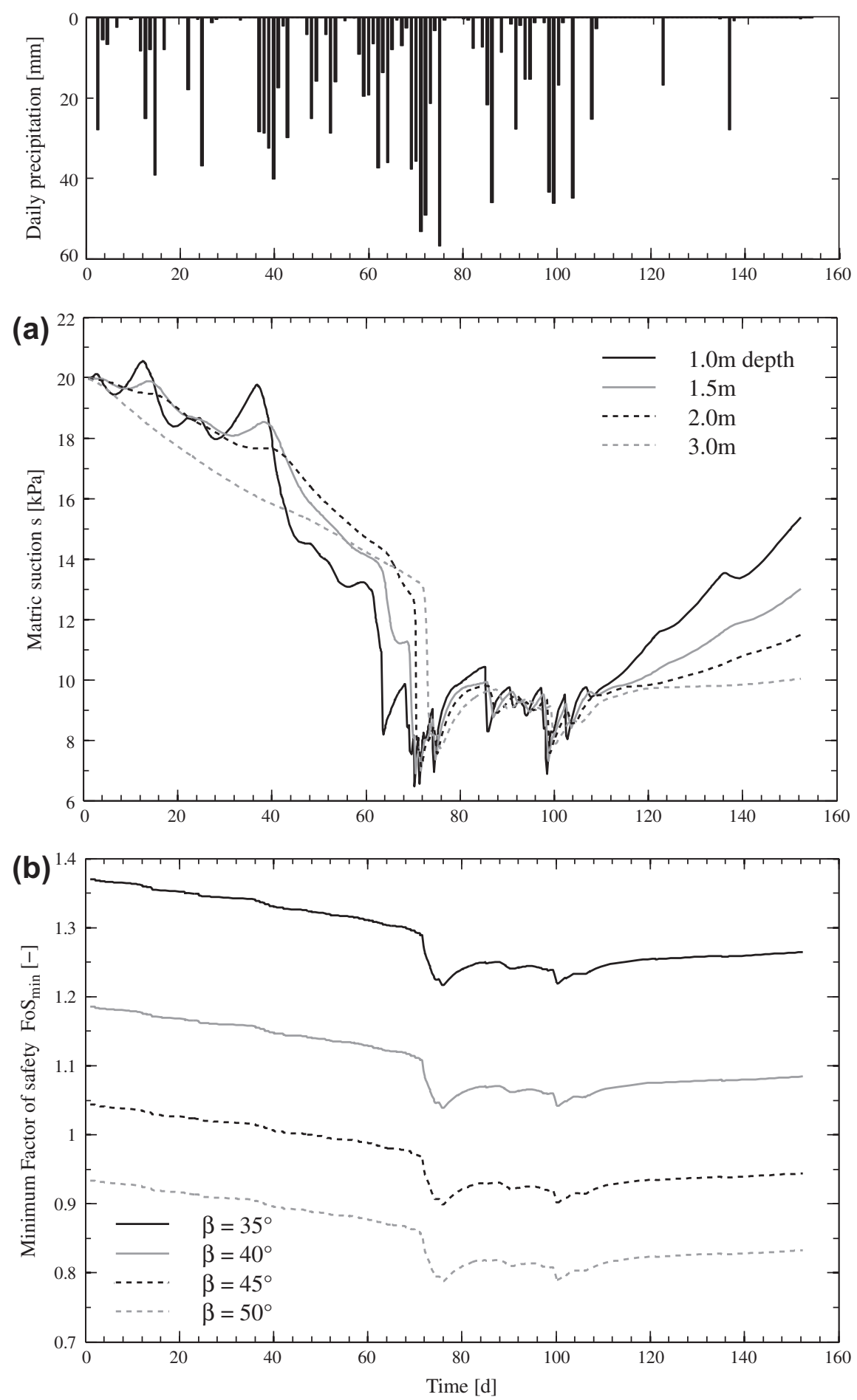

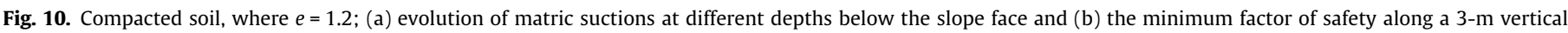
profile for different slope angles $(\beta)$.

decreasing degree of saturation (see Eq. (8)), matric suctions are not able to fully re-establish until the beginning of the dry season. As expected, the safety factors follow the same trend.

Contrary to case A, the matric suction fluctuations attenuate with increasing depths in case B (Fig. 10a). At a depth of $3 \mathrm{~m}$, the matric suctions decrease steadily until mid-September (day 70), when a rapid, substantial decrease is observed. The same evolution is observed for the minimum safety factors (Fig. 10b). The rapid and strong decrease of matric suctions indicates the presence of a distinct wetting front progressing through the soil layer. Clearly, the accumulation of several rainy days has a strong impact on the pore water pressure response, which is also observed for the reference case. However, because the soil at the reference void ratio is more permeable, the rainfall intensity becomes a more significant variable. In both cases, single rainfall events, such as on October 25 (day 86), have a far smaller impact on the matric suctions and safety factors when compared to equally intense rainfall events preceded by a couple of rainy days (November 7, day 99). For the 
case of the rainfall event of October 25, the cumulative rainfall of the preceding 10 days amounts only to $38 \mathrm{~mm}$, whereas for the rainfall event of November $7,140 \mathrm{~mm}$ is reached. These results are in agreement with the observations that are reported for the neighbouring country of Nicaragua [48] and volcanic soils in other world regions [49]. Compared to the reference case, the matric suctions re-establish even slower in denser soil as a consequence of the strong decrease in permeability with decreasing degree of saturation, as described by the water relative permeability function.

\subsection{Critical pore water pressure levels and probable depths of failure}

While matric suction losses in loose, permeable soils (case A) are limited and other than loss of matric suction failure mechanisms are most likely predominant, denser soils (case B), as encountered in old landslide deposits, can present pronounced wetting fronts that decrease matric suctions to critical levels. Matric suctions at critical depths of failure are plotted against their corresponding minimum safety factors for different slope angles in Fig. 11a. Note that one specific data entry in the plots represents a one-time step in the transient analysis. The plot shows as a first result that 3-m thick soil covers remain stable at all times during the wet season of 2005 and for slope angles $\beta \leqslant 40^{\circ}$, while they become unstable for certain matric suction levels and steeper slope
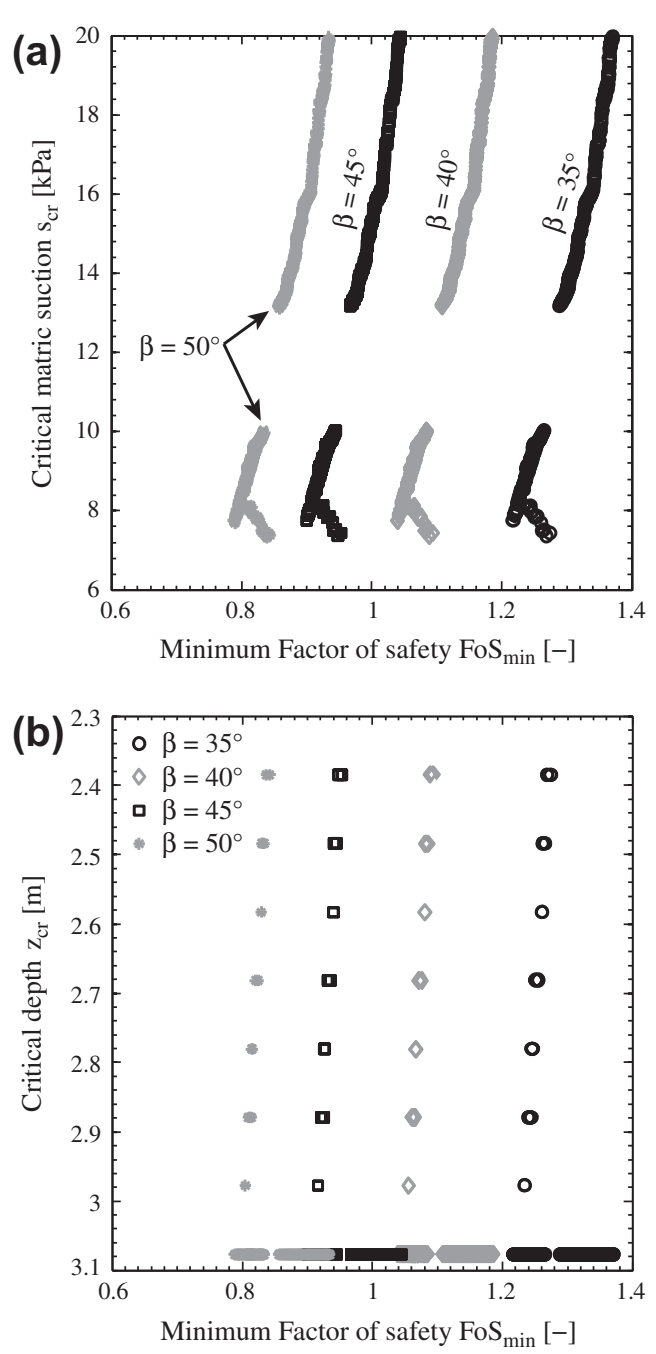

angles. The dots are arranged in two distinct clusters of higher (13-20 kPa) and lower (7-10 kPa) critical matric suction levels, which suggest that distinctive depths of potential failure surfaces associated to different characteristics of the rainfall histogram exist. To verify this assumption, the depths of potential failure surfaces are calculated and plotted against their corresponding minimum factors of safety in Fig. 11b and against their corresponding critical matric suction values in Fig. 11c. Notably, the critical depths of failure are arranged in two clusters of which one ranges from 2.4 to $3.1 \mathrm{~m}$ and the second concentrates at the lower boundary of approximately $3.1 \mathrm{~m}$. The minimum factor of safety for any slope angle $(\beta)$ occurs at the lower boundary. Fig. 11c confirms that the critical level clusters of matric suctions are associated to failures at different depths. In particular, the lowest critical levels of matric suctions at approximately $7 \mathrm{kPa}$ are associated to minimum safety factors at variable critical depths. From Fig. 11a and c, the cluster with the lowest safety factors exclusively describes the cases with rapid losses in matric suctions due to the arrival of a distinct wetting front. The cluster with higher critical matric suction levels $(13-20 \mathrm{kPa})$ is associated to the probable failures at the bottom of the ash layer due to a progressive decrease of matric suction and an increase of total stress throughout the wet season. The results in Fig. 11c also indicate that the critical matric suction levels increase with increasing soil depth. However, unless the rainfall

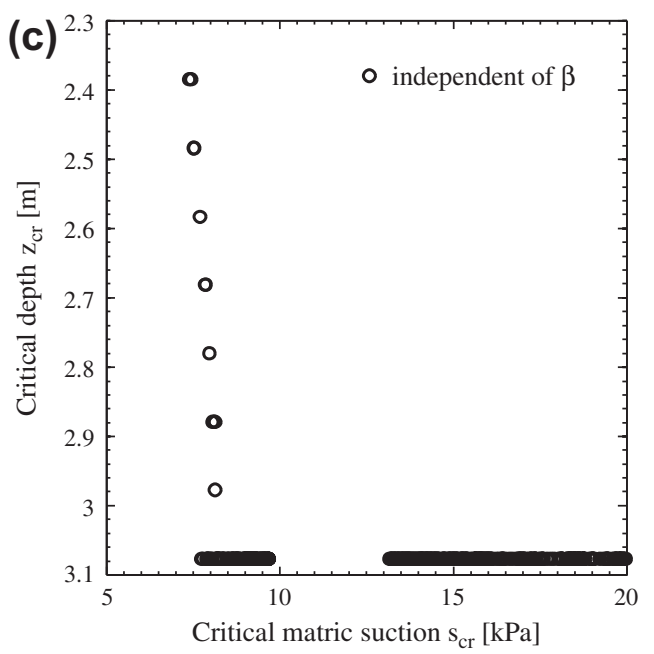

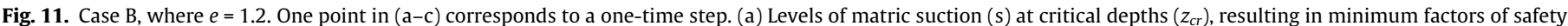

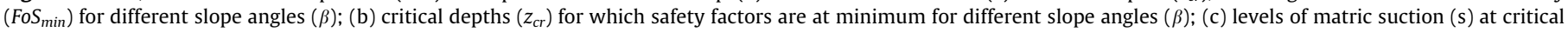
depths $\left(z_{c r}\right)$. 
intensities are high and the duration is long enough to provoke a marked top-down saturation, the probable failure plane will always occur at the bottom of the ash layer.

\section{Conclusions}

A combined finite element and infinite slope approach was used for a systematic study of potential slope failures in volcanic ashes from matric suction losses (top-down mechanism). The slope stability was evaluated considering the changes in capillary stresses (variations in matric suction and degree of saturation) and in total stress due to the weight increase from infiltrated water. The latter is not generally considered in slope stability analyses. However, for shallow volcanic ash covers that typically present high porosities, the total stress variations are non-negligible, as the wide spectrum of matric suction thresholds has demonstrated. The soil column model with its specific boundary conditions is able to represent failure mechanisms that originate from the vertical rain infiltration process. This model is suited for relatively dense soil covers, as encountered in old landslide deposits, for failure mechanisms within the soil cover that originate from relatively intense rainfall with respect to the soil's saturated coefficient of permeability and for cases where the substratum is not particularly less pervious than the soil cover.

For the considered case study, the transient slope stability analyses for the wet season of 2005 allowed studying the hydraulic response of volcanic ash to vertical rain infiltration, its sensitivity to soil dry density and effects on calculated safety factors. A soil cover thickness of $3 \mathrm{~m}$ was considered for the safety factor calculations. The following conclusions are drawn from the analyses:

1. Shorter dry periods of less than 10 days are not sufficient for reestablishing the suctions at soil depths of $>1 \mathrm{~m}$. As a consequence, the slope stability conditions worsen throughout the wet season.

2. High intensity rainfall events have a particularly negative effect on slope stability if they occur after a couple of days of significant cumulative rainfall.

3. The transient pore water pressure response of volcanic ash depends strongly on the dry soil density. This conclusion is explained by the dependency of the saturated coefficient of permeability and the water relative permeability in unsaturated conditions on the soil dry density.

4. Clusters of critical matric suction levels are associated to potential failures at different depths. For the wet season of 2005 , these critical depths are systematically located between 2.4 and $3 \mathrm{~m}$ for the assumed void ratio range $(e=1.2-1.6)$.

5 . The critical suction levels for slope stability are most often achieved at the bottom of the volcanic ash cover due to its high permeability. Potential failures within the soil cover are associated to the arrival of particularly marked wetting fronts. Considering the two cases of loose $(e=1.6)$ and compacted $(e=1.2)$ volcanic ash and the rainfall intensities of the wet season in 2005, the critical stability conditions within the soil cover occur exclusively in compacted soil.

Analytical considerations of the equilibrium equation for partially saturated infinite slopes lead to the definition of capillary stress thresholds as a function of vertical stress and slope angle. By combining the capillary stress thresholds with the soil water retention curve, it is possible to calculate critical matric suction levels and apply these thresholds to a local early warning system based on vertically distributed borehole instrumentation for matric suction or water content measurements.

\section{Acknowledgments}

The work described in this paper was supported by the project SafeLand, "Living with landslide risk in Europe: Assessment, effects of global change, and risk management strategies," under Grant Agreement No. 226479 and by the project Wandland, "Effects of wetting and drying cycles on landslide activity," under Grant Agreement No. PERG06-GA-2009-256426 in the 7th Framework Programme of the European Commission. Support was also provided by Swiss Competence Center Environment and Sustainability, TRAMM 2 Project. This support is gratefully acknowledged. The authors gratefully acknowledge Mr. James Fern for the rainfall data collection and two anonymous reviewers for their comments to improve this paper.

\section{References}

[1] Crosta GB, Dal Negro P. Observations and modeling of soil slip-debris flow initiation processes in pyroclastic deposits: the Sarno 1998 event. Nat Hazards Earth Syst Sci 1998;2003(3):53-69.

[2] Cascini L, Cuomo S, Guida D. Typical source areas of May 1998 flow-like mass movements in the Campania region, Southern Italy. Eng Geol 2008;96:107-25.

[3] Fuchu D, Lee CF, Sijing W. Analysis of rainstorm-induced slide-debris flows on a natural terrain of Lantau Island, Hong Kong. Eng Geol 1999;51:279-90.

[4] Capra L, Lugo-Hubp J, Borselli L. Mass movements in tropical volcanic terrains: the case of Teziùtlan (Mexico). Eng Geol 2003;69:359-79.

[5] Crosta GB, Imposimato S, Roddeman D, Chiesa S, Moia F. Small fast-moving flow-like landslides in volcanic deposits: the 2001 Las Colinas Landslide (El Salvador). Eng Geol 2005;79:185-214.

[6] Harp EL, Reid ME, McKenna JP, Michael JA. Mapping of hazard from rainfalltriggered landslides in developing countries: examples from Honduras and Micronesia. Eng Geol 2009;104:295-311.

[7] U.S. Agency for International Development Fact Sheet \#17; 1998.

[8] Picarelli L, Olivares L, Avolio B. Zoning for flowslide and debris flow in pyroclastic soils of Campania Region based on infinite slope analysis. Eng Geol 2008;102:132-41.

[9] Montgomery DR, Dietrich WE. A physically-based model for topographic control of shallow landsliding. Water Resour Res 1994;30(4):1153-71.

[10] Wu W, Sidle RC. A distributed slope stability model for steep forested hillslopes. Water Resour Res 1995;31:2097-110.

[11] Baum RL, Savage WZ, Godt JW. TRIGRS - a Fortran program for transient rainfall infiltration and grid-based regional slope-stability analysis. U.S. geological survey open-file report 02-0424; 2002. 27 p. [2 Appendices]. <http://pubs.usgs.gov/of/2002/ofr-02-424/>.

[12] Savage WZ, Godt JW, Baum RL. Modeling time-dependent areal slope stability In: Lacerda WA, Erlich M, Fontoura SAB, Sayao ASF, editors. Landslidesevaluation and stabilization. Proceedings of the 9 th international symposium on landslides, vol. 1. Balkema, Rotterdam; 2004. p. 23-36.

[13] Lu N, Godt J. Infinite slope stability under steady unsaturated seepage conditions. Water Resour Res 2008;44:W11404. http://dx.doi.org/10.1029/ 2008WR006976.

[14] Frattini P, Crosta GB, Fusi N, Dal Negro P. Shallow landslides in pyroclastic soils: a distributed modeling approach for hazard assessment. Eng Geol 2004;73:277-95.

[15] Baum RL, Coe JA, Godt JW, Harp EL, Reid ME, Savage WZ, et al. Regional landslide-hazard assessment for Seattle, Washington, USA. Landslides 2005;2:266-79.

[16] Godt JW, Baum RL, Savage WZ, Salciarini D, Schulz WH, Harp EL. Transient deterministic shallow landslide modeling: requirements for susceptibility and hazard assessment in a GIS framework. Eng Geol 2008;102:214-26.

[17] Eichenberger J. Geomechanical modelling of rainfall-induced landslides in partially saturated slopes [dissertation]. Ecole Polytechnique Fédérale de Lausanne (EPFL); 2012.

[18] Ferrari A, Eichenberger J, Fern J, Ebeling P, Laloui L. Experimental and numerical analysis of an unsaturated volcanic ash deposit for the establishment of an early warning system in a quarry in Costa Rica. In: ASCE geocongress: state of the art and practice in geotechnical engineering, Oakland, March 25-29; 2012. p. 2512-21.

[19] Eichenberger J, Ferrari A, Laloui L. Rainfall thresholds for shallow landslides based on a numerical analysis. In: Malet J-P, Glade T, Casagli N, editors. Mountain risks: bringing science to society, Strasbourg, France, CERG Editions; 2010, p. 67-72.

[20] Eichenberger J, Nuth M, Laloui L. Modelling landslides in partially saturated slopes subjected to rainfall infiltration. In: Laloui L, editor. Mechanics of unsaturated geomaterials. John Wiley \& Sons; 2010. p. 235-49.

[21] Klubertanz G, Laloui L, Vulliet L. Identification of mechanisms for landslide type initiation of debris flows. Eng Geol 2009;109:114-23.

[22] Losilla MP. Estudio hidrogeológico de la mina de puzolana en Llano Grande, Cartago. Informe Preparado a Solicitud de la Dirección de Geología y Minas a Holcim (Costa Rica) S. A. Ministerio de Ambiente y Energía; 2006. 27 p. 
[23] Charlier R. Approche unifiée de quelques problèmes non linéaires de mécanique des milieux continus par la méthode des éléments finis [dissertation]. University of Liège; 1987.

[24] Collin F. Couplages thermo-hydro-mécaniques dans les sols et les roches tendres partiellement saturés [dissertation]. University of Liège; 2003.

[25] Setecoop. Proyecto Mina Llano Grande - Estudio de Extraccion de Cenizas 01 Setecoop y Holcim (Costa Rica) S.A.; 2006. 11 p.

[26] Pirone M. Analysis of slope failure mechanism in unsaturated pyroclastic soils based on testing site monitoring [dissertation]. Universita' Degli Studi di Napoli Federico II; 2009.

[27] Murillo Muñoz RE. Estudio de intensidades de lluvia en la cuenca del río Virilla [dissertation]. Universidad de Costa Rica; 1994.

[28] Nuth M, Laloui L. Advances in modelling hysteretic water retention curve in deformable soils. Comput Geotech 2008;35:835-44.

[29] Sorbino G, Foresta V. Unsaturated hydraulic characteristics of pyroclastic soils In: Proceedings of the 3rd international conference on unsaturated soils, Recife, Brasil, vol. 1. Balkema, Rotterdam; 2002. p. 405-10.

[30] Van Genuchten MT. A closed-form equation for predicting the hydraulic conductivity of unsaturated soil. Soil Sci Soc Am J 1980;44(5):892-8.

[31] Kunze RJ, Kirkham D. Simplified accounting for membrane impedance in capillary conductivity determinations. Soil Sci Soc Am J 1962;26(5):421-6.

[32] Gardner WR. Calculation of capillary conductivity from pressure plate outflow data. Proc Soil Sci Soc Am 1956;20:317-20.

[33] Brooks RH, Corey AT. Hydraulic properties of porous media. Hydrology papers 3, Colorado State University, Fort Collins, Colorado; 1964.

[34] Skempton AW, DeLory FA. Stability of natural slopes in London clay. In: Proceedings of the international conference on soil mechanics and foundation engineering, vol. 4. London II; 1957. p. 378-81.

[35] Bishop AW. The principle of effective stress. Tecnisk Ukeblad 1959;39:859-63.

[36] Nuth M, Laloui L. Effective stress concept in unsaturated soils: clarification and validation of a unified framework. Int $\mathrm{J}$ Numer Anal Meth Geomech 2008;32:771-801.

[37] Bishop AW, Blight GE. Some aspects of effective stress in saturated and partly saturated soils. Géotechnique 1963;13(3):177-97.
[38] Schrefler BA. The finite element method in soil consolidation (with applications to surface subsidence) [dissertation]. University College of Swansea; 1984

[39] Laloui L, Nuth M. On the use of the generalised effective stress in the constitutive modelling of unsaturated soils. Comput Geotech 2009;36(12):20-3.

[40] Alonso EE, Pereira JM, Vaunat J, Olivella S. A microstructurally based effective stress for unsaturated soils. Géotechnique 2010;12:913-25.

[41] USACE. Slope stability. Engineering manual 1110-2-1902, Department of the Army, Corps of Engineers, Washington, DC, 2003; <www.usace.army.mil/inet/ usacoe-docs/eng-manuals/em1110-2-1902/entire.pdf>.

[42] Griffiths DV, Huang J, deWolfe GF. Numerical and analytical observations on long and infinite slopes. Int J Numer Anal Meth Geomech 2011;35:569-85.

[43] Waylen PR, Quesada ME, Caviedes CN. Temporal and spatial variability of annual precipitation in Costa Rica and the Southern Oscillation. Int J Climatol 1996;16(2):173-93.

[44] NOAA Satellite and Information Service, National Environmental Satellite, Data, and Information Service (NESDIS), National Climatic Data Center (NCDC) Climate Data Online. Web, daily rainfall data; $2011 . \quad<$ http:// www7.ncdc.noaa.gov/CDO/cdo> [accessed 08.04.11].

[45] Fern J. Geomechanical analysis for the establishment of an early warning system for shallow landslides in a volcanic ash deposit [Master Project]. Ecole Polytechnique Fédérale de Lausanne (EPFL); 2011.

[46] Rahardjo H, Ong TH, Rezaur RB, Leong EC. Factors controlling instability of homogeneous soil slopes under rainfall. J Geotech Geoenviron Eng 2007;133(12):1532-43.

[47] Mualem Y. A new model for predicting the hydraulic conductivity of unsaturated porous media. Water Resour Res 1976;12:513-22.

[48] Devoli G, Strauch W, Chávez G, Hoeg K. A landslide database for Nicaragua: a tool for landslide-hazard management. Landslides 2007;4:163-76.

[49] Pagano L, Picarelli L, Rianna G, Urciuoli G. A simple numerical procedure for timely prediction of precipitation-induced landslides in unsaturated pyroclastic soils. Landslides 2010;7:273-89. 